\title{
Integridad electoral para la calidad democrática
}

\author{
Manuel Alcántara Sáez* \\ Ana Marcela Paredes Encalada**
}

https://doi.org/10.35242/RDE $2022 \quad 22 \quad 33 \quad 10$

Nota del Consejo Editorial

Recepción: 22 de octubre de 2021.

Revisión, corrección y aprobación: 14 de enero de 2022.

Resumen: Realiza un estudio de la cultura democrática de confianza que las instituciones electorales han logrado para evitar su injerencia y falta de imparcialidad, y así legitimar los procesos electorales. Centra su análisis en el Estado ecuatoriano que por medio de sus organismos electorales no ha alcanzado la ansiada integridad electoral para un ejercicio pleno democrático; para esto, se realiza una comparación sobre los elementos diferenciadores entre países de centro, Suramérica y la Región Andina, a saber, Costa Rica, Chile y Ecuador. Inicia con un repaso del origen de las instituciones electorales en la región, continúa con un estudio de la idoneidad de la integración de los organismos electorales, para finalizar con los requisitos mínimos por considerar para la integridad electoral en una democracia.

Palabras clave: Cultura democrática / Organismos electorales / Conservación del acto electoral / Imparcialidad / Nombramientos / Ecuador / Chile / Costa Rica.

\begin{abstract}
It conducts a study of the democratic culture of confidence that electoral institutions have achieved to avoid their interference and lack of impartiality and thus legitimize electoral processes. It focuses its analysis on the Ecuadorian State which, through its electoral bodies, has not achieved the desired electoral integrity for a full democratic exercise, for this purpose the research makes a comparison on the differentiating elements between countries of the Center, South America, and the Andean Region, namely Costa Rica, Chile, and Ecuador. It begins with a review of the origin of electoral institutions in the region, continues with a study of the adequacy of the integration of electoral bodies, to finalize the minimum requirements to consider for electoral integrity in a democracy.
\end{abstract}

Key Words: Democratic culture / Electoral bodies / Preservation of the electoral act / Impartiality / Appointments / Ecuador / Chile / Costa Rica.

\footnotetext{
* Español, politólogo, correo malcanta@usal.es. Doctor en Ciencias Políticas por la Universidad Complutense de Madrid, España y Universidad de Salamanca, España. Ha dictado cursos en distintas universidades españolas, en el Centro de Estudios Constitucionales en Madrid y en universidades extranjeras: Georgetown University, Tulane University, Sciences Po (Lille), Flacso-Ecuador, Universidad Pontificia Bolivariana (Medellín), entre otras.

** Ecuatoriana, administradora pública, correo ampe14@hotmail.com. Candidata a doctora en Estado de Derecho y Gobernanza Global por la Universidad de Salamanca. Instituto de Altos Estudios Nacionales (IAEN), Ecuador. Coordinadora de la Maestría en Derecho. Mención en Derecho Electoral y Régimen Democrático. Observadora internacional electoral en Argentina, Chile, Costa Rica, Bolivia, Guyana, Rusia, Bosnia-Herzegovina y El Salvador. Observadora para la democracia en la oficina de IDEA International en la sede de Naciones Unidas en Nueva York.
} 


\section{DERECHO ELECTORAL}

\section{INTRODUCCIÓN}

A partir de la tercera ola de democratización que comenzó en América Latina y el Caribe (a excepción de Cuba), en 1978, desde entonces, la región ha experimentado una profunda transformación democrática (IDEA Internacional, 2019). Son varios los países que han reinventado las competencias y los actores electorales en un afán de transitar hacia organismos más idóneos para su función. Sin embargo, esta reinvención no ha garantizado, en todos los casos, instituciones que aporten a una cultura democrática de confianza; por el contrario, la posible injerencia y falta de imparcialidad en estos organismos han provocado serias crisis que deslegitiman la función electoral (caso Venezuela en 2020) ${ }^{1}$.

En sentido contrario, la experiencia de otros países de la región, como es el caso de Costa Rica, da cuenta de modelos más sólidos, que han requerido de varios años para lograr su institucionalización, lo cual repercute en la confianza otorgada por la población hacia dichas instituciones y sus representantes (Picado, 2018).

Según lo señala Kofi Annan: Las elecciones son la base de la democracia. Cuando se conducen con integridad, permiten a los ciudadanos tener voz en cómo y por quién son gobernados (Kofi Annan Foundation, 2018, p. 1). ¿Cómo se construye esta integridad? y ¿cuáles son los elementos capaces de aportar o disminuirla? son las preguntas que serán analizadas en la presente investigación.

Los organismos electorales (OE) funcionan de manera distinta en cada país, como respuesta a su contexto y cultura de participación; dentro del mismo continente las variopintas estructuras y experiencias responden a una historia disímil en la que la construcción de la confianza en las instituciones del Estado no es una casualidad.

Por otro lado, este artículo persigue encontrar mecanismos comparables entre los diferentes países del mundo; el contraste de las experiencias aportará en un análisis comparado con una reflexión crítica revindicativa. Cuando Sartori (1994) se refiere a los límites al momento de proponer una comparación, precisamente enfatiza en la necesidad de no incluir cualquier elemento en una categoría, solo por seguir una

\footnotetext{
1 Ver: https://elpais.com/internacional/2020-08-26/juristas-y-funcionarios-electorales-piden-postergar-laselecciones-parlamentarias-en-venezuela.html
} 


\section{DERECHOELECTORAL}

predeterminación. Por esto, los países seleccionados no solo pertenecen a un mismo continente, sino también presentan elementos tanto de comparación como de contraste..

Pese a que los tres países seleccionados no pertenecen a una misma región, vale la pena contrastar diferentes dimensiones y subdimensiones en materia electoral, cuestionando si es posible la medición entre países de diferentes regiones dentro del mismo continente (Hooghe, Marks y Schak, 2016). Puntualmente, este análisis demostrará cómo el Estado ecuatoriano a través de sus organismos electorales no ha logrado alcanzar todos los elementos que contribuyen a la ansiada integridad electoral, lo que invita a repensar sus orígenes y alternativas que aporten al ejercicio de una democracia plena. Esto a fin de contribuir con una pincelada sobre los elementos diferenciadores entre países de centro, Suramérica y la Región Andina: Costa Rica, Chile y Ecuador. Si bien son tres países pequeños y pertenecen a un mismo continente, examinar su historia y contextos particulares permitirá analizar comparativamente, los elementos que contribuyen a la confianza institucional.

\section{LA IDONEIDAD EN LA INTEGRACIÓN DE LOS ORGANISMOS ELECTORALES EN EL CONTEXTO CONTEMPORÁNEO}

La forma como se organicen los países para conformar sus organismos electorales responde en gran medida a su historia, experiencias previas y afán de aportar en sus democracias.

En el caso ecuatoriano, la Constitución de 2008 pretendía superar los excesos que cometieron los partidos políticos que manejaban al organismo de administración electoral previamente. La nueva figura de función electoral se conformaría con dos instituciones: un consejo nacional encargado de los aspectos administrativo-electorales y un tribunal contencioso electoral, que se encargaría de los asuntos jurisdiccionales. En los dos casos, su conformación se sujetaría a un concurso público de méritos y oposición.

La propuesta, que provino de una serie de debates nacionales con incidencia en la Asamblea Constituyente y que representaba un viraje en 


\section{DERECHO EIECTORAL}

la conducción de la denominada partidocracia ${ }^{2}$, suponía un nuevo momento para el país, en el que una revolución ciudadana ${ }^{3}$ imbricaba una serie de replanteamientos, actores y conducción del país. Al mismo tiempo, el carácter ciudadano invitaba a nuevos actores a ser parte de sus poderes, que prometían marcar un antes y un después en la historia nacional.

La posibilidad de abrir un concurso público de méritos y oposición para conformar la función electoral tuvo un efecto alentador en muchos sectores de la población desmarcados del sector público. De otro lado, la posibilidad de que un Consejo de Participación Ciudadana ${ }^{4}$ estuviera a cargo de su organización, representaba de igual manera un nuevo momento, en el que actores ajenos al quehacer público cumplirían sus funciones de mejor manera que quienes los antecedieron y se vinculaban a la política del país.

El apartidismo representaba un indicador de idoneidad para los cargos, y su suigéneris conformación hacía pensar que dichos actores cumplirían un rol independiente en las funciones.

Esta nueva forma de organización trajo consigo nuevos problemas, desaciertos y desconfianza, aún más exacerbada en sectores que dieron su voto de confianza y reconocieron que, pese al aparataje jurídicoinstitucional que garantizaba el cumplimiento de los principios constitucionales, en la realidad se replicaban aquellas prácticas deslegitimadas de la partidocracia. El resultado, entonces, no fue despartidizar al sector electoral, sino unificarlo con una sola tendencia, con intereses absolutistas. Pese a que constitucionalmente, el artículo 217 en su parte pertinente señala que la función electoral: "Se regirá por principios de autonomía, independencia, publicidad, transparencia, equidad, interculturalidad, paridad de género, celeridad y probidad".

\footnotetext{
${ }^{2}$ Término utilizado peyorativamente para referirse a la monopolización de los poderes por parte de los partidos políticos.

${ }^{3}$ La revolución ciudadana es un término que se empezó a utilizar en Ecuador en enero de 2007, cuando Rafael Correa asumió la Presidencia del país. Ver: https://elpais.com/internacional/2014/01/19/actualidad/ 1390110134_594343.html

${ }^{4}$ El Consejo de Participación Ciudadana y Control Social (CPCCS) fue creado por la Asamblea Constituyente de Montecristi en 2008. El expresidente Rafael Correa lo llamó el quinto poder. Es una institución independiente que forma parte de la función de transparencia y control social; al igual que la Defensoría del Pueblo, las superintendencias de bancos, compañías y comunicación y la Contraloría General del Estado. Ver: https://gk.city/2019/09/05/que-es-consejo-participacion-ciudadana-control-social/
} 


\section{DERECHOELECTORAL}

La organización de un concurso de méritos y oposición representaba una cortina de humo que encubría un solo mérito necesario para integrar estos nuevos organismos: ser miembro de la revolución ciudadana o parecerlo, es decir, quien no fuese simpatizante tendría la posibilidad de hacerlo en el transcurso del tiempo, y quien se opusiera a sus postulados quedaba descartado y, además, descalificado.

Un régimen autoritario puede contar con instituciones democráticas; sin embargo, no basta con que una democracia contenga los atributos propuestos por Shumpeter o Dahl para determinar que funciona. Se necesita, además, respetar y garantizar la participación y decisión del otro, de aquel que no gana, de aquel que no es parte del Gobierno y que, en respeto de esa igualdad de participación, merece que sus derechos políticos y civiles estén garantizados, incorporando los elementos de: elecciones limpias e institucionalizadas y un conjunto básico de libertades como los elementos que contribuyan a un régimen democrático (O 'Donnell, 2007), con la necesaria digresión entre el país (todo) y su régimen (parte), concepto que durante el proceso descrito no fue asumido con la diferenciación que el caso ameritaba.

La esperanza de nuevos cuadros apolíticos al mando de la función electoral devino en el período con mayor desconfianza y menor legitimidad de estas instituciones. El estilo jerárquico vertical en donde la cabeza de la función es quien ejerce como autoridad administrativa y nominadora depende de la voluntad demócrata de quien ejerza este cargo para incluir o no prácticas internas de participación y consenso, a fin de que resulte más ágil lograr el respaldo de tres de los cinco consejeros que conforman el cuerpo colegiado y con ello decidir sobre temas de fondo ${ }^{5}$. El tiempo máximo que podría ejercer su cargo un consejero sería de seis años, pues el sistema prevé que a mitad de período (es decir a los tres años) se realizará un sorteo para reemplazar a dos de los cinco integrantes, con la salvedad de que no podrán ser reelegidos.

Es decir, aunque la propuesta apartidista y ciudadana tenía la capacidad de sintonizar de manera más efectiva con las demandas sociales, en la

\footnotetext{
${ }^{5}$ El Consejo Nacional Electoral y el Tribunal Contencioso Electoral ecuatorianos están conformados por cinco consejeros / jueces principales y cinco suplentes que deberán elegirse constitucionalmente a través de concurso público de méritos y oposición.
} 


\section{DERECHO ELECTORAL}

práctica, tuvo un rol consecuente con su régimen, lo que deterioró la imagen y confianza con los organismos electorales ecuatorianos ${ }^{6}$.

Con el afán de contrastar el mismo período con un país centroamericano, analizamos el caso de Costa Rica que aprobó un Código Electoral en 2009. Sin embargo, en lo referente al diseño de su administración electoral, se mantuvo vigente su Constitución Política de 1949 que buscaba independencia, imparcialidad y profesionalización en sus organismos, como respuesta a las malas experiencias previas de fraude electoral (1947-1952) (Picado, 2018).

El Poder Judicial costarricense selecciona mediante concursos abiertos a los tres magistrados propietarios ${ }^{7}$ y seis suplentes que conforman el Tribunal Supremo de Elecciones (TSE) (a diferencia de Ecuador, este es el único organismo encargado de la administración y jurisdicción en materia electoral) y se requiere de votación calificada de al menos dos tercios del total de miembros de la Corte Suprema de Justicia ${ }^{8}$. A más de su calificación motivada, el modelo costarricense implementa un mecanismo de renovación parcial cada dos años, el cual reconoce la importancia de la experiencia en un sector tan especializado como lo es el electoral. Extraordinariamente, ante elecciones nacionales y municipales, el TSE se amplía con dos de sus magistrados suplentes para en ese periodo formar un tribunal de cinco miembros propietarios (Villalobos, 2019). La posibilidad de renovación en sus cargos ha permitido, en el caso de algunos magistrados, permanecer hasta veinticuatro años en el cargo (Picado, 2018).

Contrariamente al caso ecuatoriano, en Costa Rica su organismo de administración electoral (OAE) goza del primer lugar al momento de establecer el nivel de confianza que tienen sus ciudadanos. En una consulta realizada en 2011 por un grupo calificado de investigadores este aporte investigativo sostiene que:

La ciudadanía tiene mayor confianza en los poderes del Estado que percibe ajenos a la política: el Tribunal Supremo de Elecciones y los Tribunales de Justicia y, en segundo lugar, en aquellas instituciones que tienen funciones ejecutivas: la

\footnotetext{
$6 \quad$ Ver: https://www.expreso.ec/actualidad/ana-marcela-paredes-Idquo-excesiva-propaganda-cnecontraproducente-rdquo-74552.html

7 El término propietario es asimilado como principal en otros países.

${ }^{8}$ La Corte Suprema de Justicia costarricense está integrada por 22 magistrados.
} 


\section{DERECHO ELECTORAL}

presidenta y sus ministros y la municipalidad de su cantón; mientras que los niveles más bajos de confianza corresponden a aquellas instituciones que se ocupan más de las diferencias, disputas y conflictos propiamente políticos: los y las diputadas en la Asamblea Legislativa y los partidos políticos. (Fernández y otros, 2012, p. 35).

El Servicio Electoral de Chile, según lo establece el artículo 87 de la Ley Orgánica Constitucional sobre Sistema de Inscripciones Electorales y Servicio Electoral, es un organismo autónomo, con personalidad jurídica y patrimonio propio, cuyo objeto es cumplir con las funciones señaladas en la ley, y que se relacionará con el presidente de la República a través del Ministerio del Interior. Se le considera continuador y sucesor legal de la Dirección de Registro Electoral, por lo que las referencias hechas en la legislación y reglamentación vigentes al Registro Electoral, se entenderán también hechas al Servicio Electoral (artículo 89) (Quintero, 1989).

El Consejo Directivo del Servicio Electoral es un órgano colegiado de cinco miembros, designados por el presidente de la República, previo acuerdo del Senado, adoptado por los dos tercios de sus miembros en ejercicio.

Según el estudio de opinión pública Latinobarómetro, los órganos electorales de Chile, SERVEL y TRICEL obtuvieron, dentro de 18 países $^{9}$ el tercer lugar de confianza latinoamericana, según la percepción de sus ciudadanos ${ }^{10}$. Comparte este lugar con Costa Rica, país cuyos sistemas de conformación difieren entre sí.

La idoneidad de los consejeros y jueces electorales de Ecuador, Chile y Costa Rica no se garantiza por el mecanismo utilizado para su elección, tampoco la creación de nuevas instituciones lo hacen. Podríamos describir una a una las características de cada sistema y técnicamente sus aparatajes institucionales podrían coincidir en una lógica garantista de sus derechos electorales; sin embargo, dependiendo del momento y su contexto, la ingenuidad de un niño puede garantizar la idoneidad para su selección final, según la anécdota referida con anterioridad. La pregunta que surge es: ¿es idóneo para quién? ¿Según qué características?

\footnotetext{
${ }^{9}$ El desglose de resultados de 2015 es: Uruguay $73 \%$, Colombia $62 \%$, Chile 56 \%, Costa Rica 56 \%, República Dominicana $55 \%$, Panamá $51 \%$, Perú $46 \%$, Paraguay $45 \%$, México $43 \%$, Ecuador $39 \%$, Argentina $39 \%$, Brasil $35 \%$, Guatemala $34 \%$, Bolivia $34 \%$, Nicaragua $33 \%$, Venezuela $31 \%$, El Salvador $28 \%$, Honduras 22 $\%$. Promedio Latinoamérica: $44 \%$.

10 https://www.servel.cl/por-primera-vez-servel-es-evaluado-por-latinobarometro/
} 


\section{DERECHO ELECTORAL}

En la historia ecuatoriana más reciente, se consideró que la forma descrita de organización no garantizaba aquella idoneidad, y de manera interina se conformó un nuevo Consejo de Participación que eligió a una nueva función electoral. En este capítulo de la historia, la idoneidad la proveía un adulto mayor de ochenta y ocho años de edad, de notoria probidad, con probada trayectoria política e intachable proceder, que al término de sus funciones falleció, y su legado fue continuado por nuevos integrantes, cuyo mérito radica en su oposición al período de Correa o, al igual que en el caso descrito anteriormente, que aparente serlo. Desde esta nueva conformación a la fecha, el país ha contado con autoridades electorales interinas y actualmente representantes de organizaciones políticas y sociedad civil, es decir, una suerte de composición híbrida que busca desmarcarse del período anterior.

El referido proceso no logró mejorar los niveles de confianza con el organismo, habiéndose suscitado un caso particular en enero de 2021; un mes antes de las elecciones presidenciales, un juez constitucional destituyó a la presidenta y tres integrantes del Consejo; sin embargo, los consejeros continúan en funciones bajo el argumento de prioridad en la organización de los comicios. A muy pocos ciudadanos les preocupa conocer cómo se integra este organismo, y si representa o no intereses de tan solo cuatro de las más de doscientas organizaciones políticas registradas en el país. El nivel de credibilidad ha bajado ostensiblemente ${ }^{11}$ tras un llamado a juicio político por presunta corrupción ${ }^{12}$ del que salió librada su actual presidenta.

En la actualidad, de manera diligente el CNE estuvo a cargo del mapeo y logística para el plan de vacunación COVID-19 en Ecuador, función no contemplada en el Código de la Democracia, apoyando directamente al Gobierno en sus competencias. Frente a una pandemia, es complejo precisar hasta dónde deberían llegar las competencias de cada función; contrariamente, todos los esfuerzos son válidos al momento de sumar apoyos frente a una causa común. Lo que se puede leer entre líneas es este afán diligente de un organismo electoral que suma puntos para ganarse la confianza del Gobierno y el país.

\footnotetext{
${ }^{11}$ Ver: https://notimundo.com.ec/cesar-monge-la-presidenta-del-cne-carece-de-credibilidad/

12 Ver: https://www.planv.com.ec/ideas/ideas/diana-atamaint-juicio-politico
} 


\section{DERECHO ELECTORAL}

\section{REQUISITOS MÍNIMOS PARA CONSIDERAR INTEGRIDAD ELECTORAL EN UNA DEMOCRACIA}

Según se detalla en el acápite anterior, constitucionalmente los tres países cuentan con principios sólidos basados en independencia, imparcialidad, profesionalización, autonomía, publicidad, transparencia, equidad, interculturalidad, paridad de género, celeridad y probidad; sin embargo, en la práctica, bastaría con cumplir la recomendación otorgada por la Comisión Global sobre Elecciones, Democracia y Seguridad de 2012: "la clave no es una independencia formal, sino una libertad de acción verdadera" (Global Commission on Elections, Democracy and Security, 2012) para asegurar que las elecciones que se desarrollen en un país garanticen a sus ciudadanos los grandes desafíos que enfrenta la comunidad internacional, que en palabras de Kofi Annan representan: "la gobernanza democrática y el empoderamiento de la ciudadanía eran elementos integrales para logro del desarrollo sostenible, la seguridad y la paz duradera" (Kofi Annan Foundation, 2020, p. 1).

La historia, su reconocimiento y la cultura política de los tres países analizados en este ensayo responden a contextos diferenciados, elementos que han funcionado muy bien en Costa Rica, como por ejemplo, la alternancia de sus magistrados cada determinado tiempo para conformar su cuerpo colegiado, han significado motivo de controversia en Ecuador. Es decir, es complejo prescribir o intentar seguir un modelo que ha funcionado en otros países con algunas similitudes.

En el caso chileno, conservar a un mismo funcionario que se mantuvo desde antes del período dictatorial, durante 40 años, encabezando el Servicio Electoral es motivo de debate y controversia. Por un lado, la experiencia sostenida en la temática podría convertirse en una garantía; sin embargo, por el contrario, hay voces que sostienen que esta permanencia podría ser sinónimo de inmovilismo electoral ${ }^{13}$, si este factor influye en la confianza con el organismo, es un asunto que no compete exclusivamente a la variable temporal.

El análisis busca puntualizar aquellos valores mínimos sobre los cuales se puede edificar una propuesta orientadora, caracterizando su implicación y posibles consecuencias, pues, como se ha ejemplificado previamente, una acción bien intencionada puede tener repercusiones opuestas a las

${ }^{13}$ https://www.elmostrador.cl/noticias/pais/2009/09/14/el-guardian-del-inmovilismo-electoral/ 


\section{DERECHO ELECTORAL}

planificadas si no se controla en su justa dimensión; tomando la metáfora utilizada por Yanina Welp y Uwe Serdült en su libro "La dosis hace el veneno", la diferencia entre un fármaco y un veneno sería la dosis administrada (Welp y Serdült, 2014).

Conscientes de la variopinta amalgama de factores que influyen en una democracia, los elementos mencionados a continuación condensan los grandes retos para una democracia con integridad, según las recomendaciones de la Comisión Global sobre Elecciones, Democracia y Seguridad de septiembre 2012, que en su parte pertinente mencionan la necesidad de resolver cinco grandes problemas:

1. Construir un Estado de derecho que afiance los derechos humanos y la justicia electoral.

2. Crear organismos electorales (OE) profesionales y competentes que puedan actuar con total independencia en la gestión de procesos electorales transparentes y se ganen la confianza de la población.

3. Crear instituciones y normas para la competencia multipartidaria, así como un sistema de división del poder que fortalezca la democracia y ofrezca seguridad recíproca a los contrincantes políticos.

4. Eliminar las barreras jurídicas, administrativas, políticas, económicas y sociales que dificultan la participación política universal e igualitaria.

5. Regular el financiamiento político incontrolado, oculto e indebido.

Se propone analizar en forma de indicadores cada uno de estos aspectos, cuya investigación da cuenta de tratamientos diferenciados en cada país (Ver anexo 1).

\subsection{ESTADO DE DERECHO}

Desde la Constitución de 2008, Ecuador es un país garantista que trasciende la figura de derecho por la de derechos y justicia, ampliando la capacidad participativa de la sociedad. Pese a que la norma lo ampara, culturalmente, su sociedad guarda costumbres, creencias y actitudes inconvenientes ligadas a ausencia de confianza, sociedad permisiva, desigualdad de oportunidades e inseguridad jurídica (Hurtado, 2014).

Costa Rica mantiene su Constitución de 1949, resaltando su valor de legalidad costarricense que hace efectivo el Estado de derecho y la 


\section{DERECHO ELECTORAL}

separación de funciones en un país que es culturalmente respetuoso de sus leyes.

La cultura chilena difiere enormemente de los dos casos señalados, su Constitución vigente desde 1980 ha permitido que los carabineros ejerzan, hasta el día de hoy, su represión aceptada por la sociedad; no es casual que en su escudo nacional conste la frase "por la razón o la fuerza". Más allá de los postulados constitucionales, hay una especie de acuerdo por garantizar que se cumpla el Estado de derecho, de acuerdo con el criterio de quienes han tenido el poder de dirigirlo. El derecho y la justicia son entendidos como un bien colectivo más que como una lucha personal, "lo que hace pensar que el Estado de derecho tiene aquí una raíz y una razón de ser nacional" (Bravo, 1996, p. 364).

Si bien, un requisito mínimo es garantizar el Estado de derecho en un país, este no se legitima únicamente por su legislación; son, más bien, las prácticas cotidianas las que dan sustento y sentido real a su existencia. Existe un adagio popular que se refiere a que "el papel aguanta todo", es decir, pueden la Constitución y sus normas anexas garantizar todos los derechos, pero, en la práctica, pueden encontrarse los caminos para dejarlas sin efecto.

\subsection{Organismos electorales Profesionales, competentes, INDEPENDIENTES}

Las características recomendadas por la Comisión Global pueden cumplirse parcialmente 0 , dependiendo del contexto, ser manipuladas para aparentar dichos atributos. La experiencia ecuatoriana confirma que el profesionalismo, la competencia y, lo más importante, la independencia se transforman en requisitos que pueden obviarse dependiendo del responsable de la organización del concurso. Existen postulantes que pueden llegar hasta la recta final y darse cuenta de la serie de simulacros que se ejercen para cumplir con el requisito legal sin su sustento legítimo para la ciudadanía ${ }^{14}$.

En el caso costarricense, el voto de confianza brindado al organismo electoral ha sido respetado históricamente, sus jueces probos dan cuenta

\footnotetext{
${ }^{14}$ https://www.eluniverso.com/2011/11/20/1/1355/allegados-oficialismo-frente-maximo-organismoelectoral.html
} 


\section{DERECHO ELECTORAL}

de su independencia guardando coherencia entre su discurso y su accionar.

Se coincide con Norris en su apreciación respecto a la importancia que tiene examinar la capacidad del Estado y las normas informales, el grado de profesionalismo e imparcialidad de los trabajadores públicos y la cultura burocrática más que su estructura formal-legal.

La cultura burocrática de Costa Rica difiere de la ecuatoriana, los valores de imparcialidad, efectividad, legalidad, eficiencia, transparencia e integridad aportan a una administración electoral coherente con esos valores, con lo que se evitan prácticas recurrentes de clientelismo, caudillismo y corrupción.

De otro lado, la legitimidad del sistema político chileno presenta sostenidamente bajos niveles de credibilidad. La baja legitimidad política del sistema puede relacionarse con causas coyunturales -mala gestión gubernamental y escándalos de corrupción- y subyacentes desconfianza interpersonal, desapego de la actividad política y élites cerradas- que explican la baja legitimidad, lo que contribuye al surgimiento de movimientos y liderazgos populistas, y erosiona la calidad de la democracia chilena (Araya, 2017). Pese a este escenario, el organismo electoral chileno goza de buena reputación en términos generales.

\subsection{NORMAS PARA COMPETENCIA MULTIPARTIDARIA / DIVISIÓN DE PODERES /GARANTÍA PARA OPOSITORES}

La proliferación de organizaciones políticas no es sinónimo de pluralismo en ninguno de los países analizados, su dispersión y amplitud no aportan a una cultura democrática mejor informada, al contrario, la cantidad de partidos confunde al electorado que finalmente vota por una persona independientemente de su tendencia política.

Ecuador tuvo en sus últimas elecciones 16 candidatos a la presidencia, solo un par de ellos lo hizo con el partido en el que inició. Los partidos nuevos tienen baja probabilidad de subsistir y la competencia final la encabezó un excandidato, banquero, de tendencia derechista, y el candidato del expresidente Correa que continúa cosechando lealtades entre sus bases de todo el país. 


\section{DERECHO EIECTORAL}

En Costa Rica, la mayoría de las personas no se sienten representadas por los partidos políticos actuales, según la encuesta «Construyendo una Ruta Común al 2030» del Programa de las Naciones Unidas para el Desarrollo (PNUD) y la Escuela de Estadística de la Universidad de Costa Rica $(\mathrm{UCR})^{15}$.

Para las elecciones presidenciales de Chile, desarrolladas en diciembre de 2021, fueron siete los binomios participantes, con propuestas que incluyeron a coaliciones, partidos tradicionales, nuevos partidos e independientes.

La división de poderes se ha trasgredido sistemáticamente desde 2008 en Ecuador, y se ha atenuado durante el último régimen; no así en Costa Rica. La posibilidad de una oposición que ejerce su derecho a la protesta se ha garantizado durante el último gobierno en Ecuador, prueba de ello es la enorme manifestación de octubre de 2019 que obligó a su mandatario a retractarse respecto de la eliminación de los subsidios a la gasolina, sobre esto existen visiones polarizadas ${ }^{16}$. En el caso chileno, una de las principales tareas para la Convención Constitucional en Chile será reducir el hiperpresidencialismo del país ${ }^{17}$. Las pasadas protestas sociales dejaron en evidencia un excesivo uso de la fuerza pública, manteniendo un estado represivo, que aspira encontrar salidas con la nueva carta magna que tiene por delante.

Manteniéndose como una de las democracias más estables de la región, Costa Rica continúa abriendo canales de diálogo con todos los sectores entre los que se incluye a la oposición.

\subsection{Normas QUe gaRANTICEN PARTICIPACIÓN POLÍtICA UNIVERSAL E IGUALITARIA}

Los tres países han hecho esfuerzos por garantizar la inclusión de sectores tradicionalmente excluidos, personas de la tercera edad, personas privadas de libertad y, desde 2016 (en el caso de Ecuador), personas de la población LGBTI.

\footnotetext{
15 https://semanariouniversidad.com/pais/encuesta-construyendo-una-ruta-comun-al-2030/

${ }^{16}$ https://www.elcomercio.com/actualidad/libros-protestas-octubre-romo-iza.html

17 https://www.bbc.com/mundo/noticias-america-latina-57104668
} 


\section{DERECHO ELECTORAL}

El reconocimiento e inclusión de la comunidad mapuche en el escenario político chileno representa un hito importante en su democracia. Su histórico conflicto de la Araucanía podría atenuar sus niveles de confrontación con representantes en su parlamento.

La política pública ecuatoriana de voto en casa ha permitido a personas con discapacidad severa recibir la visita de juntas electorales móviles para garantizar su participación; se constituye así en una medida pionera en la región, que valora a sus votantes y les permite sentirse parte de un momento importante como lo es la jornada electoral. Esta inclusión aporta al sentir democrático diverso de estos países, pues persigue que, independientemente de su condición, el votode cada persona ciudadana sea importante, y requiere del esfuerzo del organismo electoral para garantizar su participación. Este tipo de iniciativas influyen en una cultura ciudadana mejor informada, cuyos canales de participación requieren esfuerzos adicionales que, en el caso ecuatoriano, el organismo ha garantizado.

La garantía de los derechos políticos de todos los integrantes de una sociedad busca el ejercicio de sus libertades. El concepto de "libertad" puede ocasionar un estiramiento conceptual (Sartori, 2009) que, dependiendo de su contexto, puede tener significados variados.

No todos los miembros de la sociedad pueden gozar de iguales "libertades", de ahí la necesidad de continuar innovando con iniciativas que acerquen al ciudadano a la res-pública, la cosa pública, cuyo devenir depende de la actuación de sus sociedades.

\subsection{FinANCIAMIENTO POLÍtico CONTROLADO}

La asignación estatal en los tres países promueve la fiscalización por parte de sus organismos. A diferencia de Costa Rica y Chile, esta fiscalización no se ha llevado de manera transparente en Ecuador, donde varios candidatos han solicitado prescindir de dicha asignación, sin que legalmente pueda darse cumplimiento a esta solicitud.

Al igual que con los otros factores analizados, la propuesta de financiamiento controlado serviría en un país en el que las instituciones respeten la separación de funciones, y el control sea real. La reciente reforma democrática de 2020 en Ecuador buscaba sincerar el 


\section{DERECHO ELECTORAL}

financiamiento de las campañas electorales; sin embargo, aún no hay evidencia de su utilidad.

De otro lado, el financiamiento a través de medios digitales no es controlado por los organismos electorales de los países analizados, por lo que se constituye en un espacio abierto, no controlado, que especialmente en tiempo de pandemia ha influido directamente en las decisiones electorales.

\section{Conclusiones}

A través de este recorrido por los contextos de Ecuador, Costa Rica y Chile, quedan en evidencia una serie de elementos necesarios para rectificar y ganar la confianza que reviste la integridad electoral. Un primer esbozo respecto a los elementos diferenciadores que han marcado la vida democrática de estos tres países, con fuertes repercusiones en su integridad electoral, son:

- Los procesos lentos, reflexivos, que respeten sus bases normativas históricas son un factor de éxito en Costa Rica, en donde el aparataje institucional sigue vigente desde 1949. En Ecuador son comunes los interinazgos nocivos en un campo tan especializado como lo es el electoral; esta corta permanencia de autoridades en sus cargos, sin experiencia, y que responden a un interés político, desvirtúa un accionar consecuente institucional, de la mano con las veinte constituciones que ha tenido el país ${ }^{18}$,y su necesidad de acoplar normas y actores a las circunstancias, lo que repercute en una costumbre cortoplazista ecuatoriana, en la que lo que no sirve a la primera habrá que cambiarlo prontamente. Chile se encuentra a las puertas de un cambio constitucional que deberá entrar en vigencia en el año 2022; a diferencia de los dos países mencionados, en el campo electoral, se ha caracterizado por líderes que han ejercido con larga data la función, dependiente directamente del Ministerio de Gobierno. Aún queda pendiente este debate en el marco de los cambios constitucionales sentidos y postergados en el país.

- $\quad$ En Ecuador, los ciclos de diez años que hemos transitado, desde 1997 a 2007, con siete presidentes en diez años, y luego, desde 2007 a

\footnotetext{
${ }^{18}$ http://constituyente.asambleanacional.gob.ec/documentos/biblioteca/1906.pdf
} 


\section{DERECHO ELECTORAL}

2017, con un presidente en los siguientes diez años, son indicador de aquella polarización radical que promueve cada vez en menor medida la posibilidad de construir una vía intermedia. A diferencia de Costa Rica que ha respetado el período de sus Gobiernos y su alternabilidad. Chile es un caso particular, después de su nefasta dictadura, ha respetado sus mandatarios, que cada vez cuentan con menor apoyo de sus votantes (promedio $36 \%$ ) (PNUD, 2017).

- Los actores son importantes, pero lo son también el número de estos actores que integren el organismo electoral. Costa Rica tiene tres miembros, cantidad que, dependiendo de la necesidad (períodos electorales) puede ampliarse a cinco, considerando el buen uso de sus recursos públicos y la optimización durante sus funciones. Ecuador tiene cinco miembros, de los cuales solo tres han tomado las decisiones trascendentales para la última jornada electoral, por ejemplo. La oposición de dos miembros no representa cambios importantes en las decisiones, y deja, consecuentemente, un organismo disfuncional, vertical, cuyas represalias por no sumarse a la mayoría se evidencian en despidos al personal, ocultamiento de información, entre otros, pues, finalmente es la autoridad nominadora, presidente/a quien tiene la responsabilidad administrativa, en este caso, a más de insuficientes, resulta ineficiente contar con cinco miembros si en la práctica con tres podría funcionar mejor este cuerpo colegiado.

- La fuerte influencia académica en todos los magistrados costarricenses y chilenos es un factor diferenciador con relación a Ecuador. Hasta las pasadas elecciones, solo uno de los cinco miembros del consejo estuvo vinculado a la academia, sin que eso sea un mérito real que influya en la legitimidad social.

Finalmente, el gran desafío para los organismos sigue siendo, tal como lo mencionaría Nohlen (2012): "la independencia del poder político", esta independencia ha sido larga de construir y bien ganada por Costa Rica, y contrariamente, muy cuestionada en el caso ecuatoriano, y menos en el chileno.

La posibilidad de reorientar el sinnúmero de desaciertos aplicados en Ecuador depende del consenso de varios sectores, y no únicamente de su temporal organismo electoral; marcar una ruta conciliadora representaría 


\section{DERECHO ELECTORAL}

un hito histórico diferenciador de aquellas reprochables "costumbres de los ecuatorianos" referidas con anterioridad.

En un afán de reinventar la nación, Ecuador está probando innovativos andamiajes institucionales que no aportan en la integridad ni de las elecciones ni del Estado en su conjunto, por lo que habrá que explorar alternativas intermedias que aporten en un equilibrio real de poderes y en una mejor democracia.

\section{REFERENCIAS BIBLIOGRÁFICAS}

Anríquez, G. (s. f.). Desarrollo de la democracia en Chile. Memoria Chilena. Chile: Artículos para el bicentenario.

Arana, I. (2017). Chile 2016: ¿El nadir de la legitimidad democrática? Revista Ciencias Políticas, 37(2), 305-333. Recuperado de http://dx.doi.org/10.4067/s0718-090×2017000200305

Biblioteca Nacional de Chile (s. f.). La Guerra de Arauco (1550-1656). Recuperado de http://www.memoriachilena.gob.cl/602/w3-article691.html

Bravo, B. (1996). El Estado de derecho en la historia de CHILE: por la razón o la fuerza. Santiago de Chile: Ediciones Universidad Católica de Chile.

Cascante, M. J. (Septiembre de 2010). La competencia electoral en Costa Rica y Nicaragua: diferencias multinivel, pp. 1893-1926. En XIV Encuentro de Latinoamericanistas Españoles: congreso internacional. Santiago de Compostela, España.

Castellanos, J. (Septiembre 2021). ¿Es necesaria la observación electoral en Chile? En Conferencia Americana de Organismos Electorales Subnacionales por la Transparencia Electoral. Recuperado de https://transparenciaelectoral.org/caoeste/es-necesaria-la-observacionelectoral-en-chile/

García, I. (5 de mayo, 2021). Después de 35 años, director del Servicio Electoral nombrado por Pinochet deja su cargo. El Mostrador. Recuperado de 


\section{DERECHO EIECTORAL}

https://www.elmostrador.cl/noticias/pais/2012/05/05/despues-de-35anos-director-del-servicio-electoral-nombrado-por-pinochet-deja-su-cargo/

Engel, E. (Agosto, 2019). El dinero y la política: reformas recientes en Chile. En The Dialogue Org. Recuperado de https://www.thedialogue.org/wpcontent/uploads/2019/08/Eduardo-Engel-Espa\%C3\%B1ol.pdf

Fernández, D., Alfaro, R., Raventós, C. y Fournier M. (2012). Respuestas ciudadanas ante el malestar con la política: salida, voz y lealtad. San José, Costa Rica: Tribunal Supremo de Elecciones. Instituto de Formación y Estudios en Democracia. Centro de Investigaciones y Estudios Políticos. Universidad de Costa Rica.

Freindenberg, F., Pachano, S. y Mejía, A. (2005). La ciencia política en Ecuador: un reflejo de su fragilidad democrática (1978-2005). Revista de Ciencia Política, 25(1), 147-161.

Global Commission on Elections, Democracy and Security (2012). Profundizando la democracia. Una estrategia para mejorar la integridad electoral en el mundo. Informe de la Comisión Global sobre Elecciones, Democracia y Seguridad. Suecia: Instituto Internacional para la Democracia y la Asistencia Electoral / Fundación Kofi Annan.

Gutiérrez, R. (2016). Representación legislativa, multipartidismo y carrera parlamentaria. Análisis Político.

Hooghe, L., Marks, G. y Schak, A. H. (2016). Transformation in governance. A Postfunctionalist Theory of Governance, volume II. Oxford University Press.

Hurtado, O. (2014). Las costumbres de los ecuatorianos. Quito: Planeta.

IDEA Internacional (2019). El estado de la democracia en el mundo y en las Américas 2019. Confrontar los desafíos, revivir la promesa. Estocolmo Suecia: IDEA Internacional.

Instituto Interamericano de Derechos Humanos (2017). Diccionario electoral (Serie Elecciones y Democracia). San José, C. R.: IIDH. 


\section{DERECHOEIECTORAL}

Jaramillo, M. A. (2011). El nuevo modelo de Estado en el Ecuador: del Estado de derecho al Estado constitucional de derechos y justicia (Tesis). Universidad San Francisco de Quito, Colegio de Jurisprudencia. Quito, Ecuador.

Kofi Annan Foundation. (2018). Confianza en elecciones y aceptación de resultados. Un informe de políticas de la Iniciativa por la Integridad Electoral. Switzerland: Kofi Annan Foundation.

Kofi Annan Foundation. (2020). La protección de la integridad electorlen la era digital: informe de la Comisión Kifi Annan sobre elecciones y democracia en la era digital. Switzerland: Kofi Annan Foundation

Lecuna, V. (1947). Obras Completas (Tomo I). La Habana.

Morón Urbina, J. C. (2000). Bolívar y su propuesta constitucional de 1826. Dialnet. Derecho PUCP: Revista de la Facultad de Derecho, (53), 173-243.

Muñoz-Pogossian, B. (2020). Democracia y derechos de las personas LGBTI en América Latina: reformas para garantizar el derecho a la identidad y el derecho al voto de las personas trans, 2012-20201. Derecho Electoral, https://doi.org/10.35242/RDE_2020_30_4.

Norris, P. (2014). Why electoral integrity matters? New York: Cambridge University Press.

O 'Donnell, G. (2007). Disonancias: críticas democráticas a la democracia. Buenos Aires, Argentina: Prometeo libros.

Ortiz, E. O. (1976). Costa Rica: Estado social de derecho. San José, Costa Rica. Revista de Ciencias Jurídica (29), 23-157.

Pérez, H. (2017). El laberinto centroamericano: los hilos de la historia. San José, Costa Rica: Vicerrectoría de Investigación. Centro de Investigaciones Históricas de América Central. Universidad de Costa Rica.

Picado, H. (2018). Reforma Electoral: actores, procedimiento y discurso. San José, Costa Rica: Tribunal Supremo de Elecciones. Instituto de Formación y Estudios en Democracia. Recuperado de https://www.tse.go.cr/pdf/publicaciones/Reforma-Electoral.pdf 


\section{DERECHO EIECTORAL}

Programa de las Naciones Unidas para el Desarrollo (2017). Investigadora responsable: Marcela Ríos. Investigadores del Equipo: Sebastián Madrid y Sofía Sacks. (Octubre 2017). Diagnóstico sobre la Participación Electoral en Chile Proyecto Fomentando la Participación Electoral en Chile Primera Edición. Vitacura: Max Grum.

Quintero Nader, F. (1989). El sistema electoral en Chile. Revistas Colaboración Jurídicas UNAM,(14), 63-78.

Ríos, L. (2018). El desequilibrio de los poderes. Revista de Derecho Público, (número especial), 169-190.

Rodríguez, J. E. (2006). La revolución política en la época de la independencia: El Reino de Quito, 1808-1822 (pp. 65-70 y 134-138). Quito: Corporación Editora Nacional.

Rosales, R. (2015). Problemas de la representación política y de los partidos políticos en Costa Rica: Oportunidad para un diálogo social reconstitutivo. Dialnet, 239-275.

Sánchez, C. (2021). Mirada pública n. ${ }^{\circ}$ 23. Estado de derecho. Santiago, Providencia, Chile: Instituto Res Pública.

Sartori, G. (1994). La comparación en las ciencias sociales. Madrid, España: Alianza Editorial.

Sobrado, L. A. (2011). La financiación de los partidos políticos en Costa Rica. En P. Gutierrez y D. Zovatto, Financiamiento de los partidos políticos en América Latina (pág. 225). México: Instituto Internacional para la Democracia y la Asistencia Electoral. Organización de los Estados Americanos. Universidad Nacional Autónoma de México.

Titelman, N. (18.06.2021). Cambiar o morir: la crisis terminal de los partidos políticos chilenos. Ciperacadémico. Análisis Político.

Tuesta, F. (2012). Estrategias de desarrollo y fortalecimiento de las autoridades electorales. XXVI Conferencia del Protocolo de Tikal. El Salvador: Pontificia Universidad Católica del Perú. 


\section{DERECHO ELECTORAL}

Vargas, H. (2001). Evolución del sistema electoral costarricense (1859-1870). Diálogos Revista Electrónica; 2(2). Recuperado de https://revistas.ucr.ac.cr/index.php/dialogos/article/view/6312/6014

Peña, Y. (2020). ¿Qué fue la "pacificación de la Araucanía"? La guerra del Estado de Chile contra el pueblo mapuche. Laizquierda Diario.

Villalobos, L. D. (2019). Magistratura electoral y reforma constitucional. Revista de Ciencias Jurídicas, (149), 61-72.

Welp, Y. y Serdült , U. (2014). La dosis hace el veneno. Análisis de la revocatoria del mandato en América Latina, Estados Unidos y Suiza. Quito, Ecuador: Instituto de la Democracia. 


\section{DERECHOEIECTORAL}

\section{Anexo 1}

\section{Matriz comparada Ecuador / Costa Rica / Chile}

\begin{tabular}{|c|c|c|c|}
\hline $\begin{array}{l}\text { Requisitos } \\
\text { mínimos }\end{array}$ & Ecuador & Costa Rica & Chille \\
\hline $\begin{array}{l}\text { Estado de } \\
\text { derecho }\end{array}$ & $\begin{array}{l}\text { En la Constitución de } 2008 \\
\text { se establece que Ecuador es } \\
\text { un Estado constitucional de } \\
\text { derechos y justicia, lo que } \\
\text { supone un compromiso } \\
\text { activo por parte de todos los } \\
\text { ciudadanos, quienes deben } \\
\text { procurar estar al tanto de los } \\
\text { contenidos teóricos que se } \\
\text { proponen en la Constitución } \\
\text { (Jaramillo, 2011). En teoría, } \\
\text { trascendiendo la generalidad } \\
\text { de un Estado de derecho y } \\
\text { dotando de características } \\
\text { progresistas y modernas que } \\
\text { amplían la garantía de } \\
\text { derechos en el país. }\end{array}$ & $\begin{array}{l}\text { La Constitución actual de } \\
\text { Costa Rica, vigente desde } \\
\text { 1949, establece como sus } \\
\text { valores rectores: la } \\
\text { legalidad, paz e igualdad, } \\
\text { considerando el } \\
\text { sentimiento de "legalidad } \\
\text { costarricense" como un } \\
\text { atributo de su cultura. } \\
\text { "Las constituciones de } \\
\text { Costa Rica han tenido } \\
\text { siempre una parte } \\
\text { dogmática muy generosa } \\
\text { con el individuo y sus } \\
\text { libertades, y nuestro } \\
\text { ordenamiento ha } \\
\text { perfeccionado lenta, pero } \\
\text { sostenidamente, una } \\
\text { maquinaria electoral de } \\
\text { excepcional eficiencia para } \\
\text { asegurar una auténtica } \\
\text { representación popular" } \\
\text { (Ortiz, 1976, p. 27). }\end{array}$ & $\begin{array}{l}\text { La Constitución vigente desde } \\
1980 \text { menciona como bases } \\
\text { constitucionales del Estado } \\
\text { de derecho a aquellos } \\
\text { principios que, formando } \\
\text { parte de las bases de la } \\
\text { institucionalidad, dan origen } \\
\text { al denominado "Estado de } \\
\text { derecho". Estos se } \\
\text { encuentran consagrados } \\
\text { particularmente en los } \\
\text { artículos } 6 \text { y } 7 \text { del capítulo } \\
\text { primero de la Constitución y } \\
\text { son: el principio de } \\
\text { supremacía constitucional, } \\
\text { legalidad, juridicidad y } \\
\text { responsabilidad (Sánchez, } \\
2021 \text { ). }\end{array}$ \\
\hline $\begin{array}{l}\text { Organismos } \\
\text { electorales } \\
\text { profesionales, } \\
\text { competentes, } \\
\text { independientes }\end{array}$ & $\begin{array}{l}\text { De acuerdo al análisis } \\
\text { expuesto, no todos los } \\
\text { integrantes de la función } \\
\text { electoral tienen las } \\
\text { características descritas en el } \\
\text { indicador. Incluso, si uno de } \\
\text { sus miembros tuviese alguna } \\
\text { de estas características, no } \\
\text { es relevante, frente a las } \\
\text { características de la cabeza } \\
\text { de función que es quien } \\
\text { decide en última instancia. } \\
\text { Actualmente solo uno de los } \\
\text { cinco consejeros tiene } \\
\text { vinculación con la academia, } \\
\text { y su rol es colateral. }\end{array}$ & $\begin{array}{l}\text { El caso costarricense } \\
\text { presenta una característica } \\
\text { interesante, sus miembros } \\
\text { a más de probada } \\
\text { trayectoria en el ámbito } \\
\text { democrático y/o electoral, } \\
\text { están vinculados a la } \\
\text { academia, este factor } \\
\text { aporta un nivel técnico } \\
\text { indiscutible y diferenciador. }\end{array}$ & $\begin{array}{l}\text { EI SERVEL goza de la } \\
\text { confianza social, tanto por la } \\
\text { adecuada organización de las } \\
\text { elecciones, como por los } \\
\text { esfuerzos permanentes de } \\
\text { mejoras, la actuación de las } \\
\text { partes involucradas } \\
\text { (institucionales y no } \\
\text { institucionales) y el } \\
\text { reconocimiento de sus } \\
\text { resultados por parte de la } \\
\text { gran mayoría de los actores } \\
\text { que conforman el sistema } \\
\text { político nacional. Para su } \\
\text { constatación, basta revisar } \\
\text { índices como el Index of } \\
\text { Democracy de The Economist } \\
\text { (2021), Freedom in the World } \\
\text { de Freedom House (2020) y } \\
\text { el reporte de The Electoral } \\
\text { Integrity Project 2019, por } \\
\text { citar solo algunos } \\
\text { (Castellanos, 2021). } \\
\text { Sus integrantes cuentan con } \\
\text { destacada trayectoria } \\
\text { académica para ser parte de } \\
\text { este organismo. }\end{array}$ \\
\hline $\begin{array}{l}\text { Normas para } \\
\text { competencia } \\
\text { multipartidaria }\end{array}$ & $\begin{array}{l}\text { El Código de la Democracia } \\
\text { en su art. } 306 \text { señala que: } \\
\text { Las organizaciones políticas }\end{array}$ & $\begin{array}{l}\text { El art. } 49 \text { del Código } \\
\text { Electoral define a los } \\
\text { partidos políticos como: }\end{array}$ & $\begin{array}{l}\text { El artículo } 1 \text { de la } \\
\text { Constitución Política de la } \\
\text { República de Chile señala: }\end{array}$ \\
\hline
\end{tabular}




\begin{tabular}{|l|l|}
\hline /División de & $\begin{array}{l}\text { son un pilar fundamental } \\
\text { poderes } \\
\text { /Garantía para construir un estado } \\
\text { opositores }\end{array}$ \\
$\begin{array}{ll}\text { constitucional de derechos y } \\
\text { justicia. Se conducirán } \\
\text { conforme a los principios de } \\
\text { igualdad, autonomía, } \\
\text { deliberación pública, respeto } \\
\text { a la diferencia, control } \\
\text { popular, solidaridad e } \\
\text { interculturalidad. }\end{array}$
\end{tabular}

Sin embargo, la proliferación de organizaciones políticas locales y nacionales, cerca de 300 (ver anexo 2), no inciden en una cultura participativa, por el contrario, son el medio para malutilizar el sistema garantista.

La división de poderes existe constitucionalmente otorgando a los tres poderes tradicionales la función ejecutiva, la legislativa y la judicial; y en adición, la función electoral y la de transparencia y control social.

Si bien, el actual Gobierno respeta la separación de poderes, existen líderes de estilo autoritario (de organizaciones políticas con representación en la función electoral) que ejercen el rol asumido durante el período anterior.

Comparativamente con el anterior régimen, en el actual se respeta el criterio divergente, la oposición tiene espacio para participar en iguales condiciones que quienes pertenecen al Gobierno. De hecho, en la reciente contienda electoral, el tema central continuó siendo el lado correista o no que representaron los candidatos, lo que provocó una marcada polarización, populismo vs. derecha, dejando a una izquierda vacía de ideología y bases.
"Asociaciones voluntarias sin fines de lucro, con el objeto de participar activamente en la política nacional, provincial o cantonal y cumplen una función de relevante interés público".

En Costa Rica existe una mayor flexibilidad para presentar candidaturas y mantener los partidos políticos como actores de la competencia a lo largo del tiempo (Cascante, 2010).

De los 139 partidos (ver anexo 3 ) inscritos hasta la presente fecha, los de mayor representación son: socialdemocracia, democracia cristiana, liberalismo,

conservadurismo, comunismo e izquierda del siglo XXI, y en menor proporción los dos partidos ecologistas. Más allá de su ideología, en Costa Rica los partidos políticos desde sus orígenes han sido eminentemente personalistas, en muchos casos fundados en torno a un caudillo y no a una propuesta ideológica (Gutiérrez, 2016).

El Gobierno de Costa Rica está conformado por cuatro poderes, separados e independientes entre sí: el poder ejecutivo, el poder legislativo, el poder judicial y el poder electoral que respetan el ejercicio de una nación libre, soberana, democrática e independiente.

Los grupos de oposición tienen derecho a participar y ser escuchados, sin temor a represalias.
Los partidos políticos son asociaciones autónomas y voluntarias organizadas democráticamente, dotadas de personalidad jurídica de derecho público, integradas por personas naturales que comparten unos mismos principios ideológicos y políticos, cuya finalidad es contribuir al funcionamiento del sistema democrático y ejercer influencia en la conducción del Estado, para alcanzar el bien común y servir al interés nacional. Los partidos políticos expresan el pluralismo político, concurren a la formación y expresión de la voluntad popular, son instrumento fundamental para la participación política democrática, contribuyen a la integración de la representación nacional y son mediadores entre las personas y el Estado. Los partidos políticos deberán contribuir al fortalecimiento de la democracia y al respeto, garantía y promoción de los derechos humanos reconocidos en la Constitución, en los tratados internacionales ratificados $y$ vigentes en Chile y en las leyes.

Actualmente, se encuentran 27 partidos políticos registrados a nivel nacional (ver anexo 4). La reforma al sistema de partidos de 2016 fue insuficiente porque no buscó revertir la tendencia al desarraigo de estas

organizaciones. El excesivo énfasis institucionalista evitó abrir la puerta a la discusión más relevante: su capacidad de agregación de demandas sociales (Titelman, 18.06.2021).

Aún se cuestiona la división de funciones, especialmente por la intromisión del gobierno militar y normalización a malas prácticas de desequilibrio de los poderes (Ríos, 2018). 


\begin{tabular}{|c|c|c|c|}
\hline $\begin{array}{l}\text { Normas que } \\
\text { garanticen } \\
\text { participación } \\
\text { política } \\
\text { universal e } \\
\text { igualitaria }\end{array}$ & $\begin{array}{l}\text { En } 2016 \text { se incluyó la } \\
\text { identidad de género dentro } \\
\text { de las reformas a la Ley de } \\
\text { Registro Civil, es decir, que } \\
\text { las y los ciudadanos } \\
\text { ecuatorianos pueden elegir el } \\
\text { cambio de su género por una } \\
\text { sola vez en su vida. Esta } \\
\text { reforma repercutió en la } \\
\text { posibilidad de que en el día } \\
\text { de las votaciones puedan } \\
\text { elegir la fila para votar (en } \\
\text { Ecuador las filas son } \\
\text { diferenciadas Hombre/Mujer, } \\
\text { lo que causó discriminación a } \\
\text { los géneros que están fuera } \\
\text { de este sistema binario). } \\
\text { Esta es una medida que } \\
\text { aporta a la participación } \\
\text { universal, ya que reconoce a } \\
\text { grupos de la población } \\
\text { tradicionalmente excluídos }{ }^{19} \text {. } \\
\text { Aproximadamente se han } \\
\text { realizado cerca de } 500 \\
\text { cambios de género en el país } \\
\text { hasta noviembre 2019. } \\
\text { (Muñoz-Pogossian, 2020) }\end{array}$ & $\begin{array}{l}\text { Una reforma similar en el } \\
\text { año } 2016 \text { generó un } \\
\text { cambio de género de } 430 \\
\text { casos en Costa Rica } \\
\text { (septiembre, 2019), con el } \\
\text { reconocimiento parcial o } \\
\text { integralmente de su } \\
\text { identidad de género } \\
\text { (Muñoz-Pogossian, 2020). } \\
\text { En este país las filas son } \\
\text { mixtas por lo que no hay } \\
\text { un impacto el día de las } \\
\text { elecciones. } \\
\text { Sin embargo, hay claros } \\
\text { indicios garantistas de } \\
\text { políticas inclusivas con el } \\
\text { sector LGBTI. }\end{array}$ & $\begin{array}{l}\text { En } 2019 \text { se promulgó en el } \\
\text { país la Ley de Identidad de } \\
\text { Género, que establece como } \\
\text { un derecho el reconocimiento } \\
\text { de las personas con una } \\
\text { identidad de género diversa. } \\
\text { Lamentablemente, estos } \\
\text { avances van de la mano con } \\
\text { mayores abusos homófobos y } \\
\text { transmófobos }{ }^{20} \text {. } \\
\text { Al igual que en Costa Rica, en } \\
\text { Chile las filas son mixtas. }\end{array}$ \\
\hline $\begin{array}{l}\text { Financiamiento } \\
\text { político } \\
\text { controlado }\end{array}$ & $\begin{array}{l}\text { La propuesta innovativa de la } \\
\text { Asamblea Constituyente de } \\
2008 \text { propuso dejar atrás la } \\
\text { posibilidad de que } \\
\text { únicamente puede ser } \\
\text { candidato quien tiene la } \\
\text { capacidad económica para } \\
\text { financiarse. Con la idea de } \\
\text { garantizar equidad para que } \\
\text { cualquier ecuatoriano, } \\
\text { indistintamente de su } \\
\text { condición económica pueda } \\
\text { participar, se estableció una } \\
\text { pauta publicitaria obligatoria, } \\
\text { manejada exclusivamente } \\
\text { por el Estado, es decir, con } \\
\text { recursos de los ciudadanos. } \\
\text { Finalmente, el artículo } 115 \\
\text { de la Constitución vigente } \\
\text { desde octubre de 2008 } \\
\text { estableció que "El Estado, a } \\
\text { través de los medios de } \\
\text { comunicación, garantizará de } \\
\text { forma equitativa e igualitaria } \\
\text { la promoción electoral que } \\
\text { propicie el debate y la } \\
\text { difusión de las propuestas }\end{array}$ & $\begin{array}{l}\text { En Costa Rica, la reforma } \\
\text { electoral aprobada en } 2009 \\
\text { significó avances } \\
\text { importantes para mejorar } \\
\text { la transparencia en el } \\
\text { financiamiento público y } \\
\text { privado de campañas } \\
\text { electorales y partidos } \\
\text { políticos, pero mantiene } \\
\text { carencias ostensibles en: } \\
\text { a) promover la equidad en } \\
\text { la competencia partidaria y } \\
\text { electoral, b) facilitar la } \\
\text { participación y el } \\
\text { empoderamiento de } \\
\text { diversos grupos } \\
\text { poblacionales que reflejen } \\
\text { la pluralidad social del país, } \\
\text { y c) facilitar la distribución } \\
\text { social de los recursos, de } \\
\text { modo que no se vea } \\
\text { comprometido el ejercicio } \\
\text { del gobierno o la } \\
\text { prevalencia del interés } \\
\text { público general (Rosales- } \\
\text { Valladares, 2015). }\end{array}$ & $\begin{array}{l}\text { A principios de } 2016 \text {, el } \\
\text { Congreso de Chile aprobó dos } \\
\text { importantes leyes que } \\
\text { reforman el financiamiento de } \\
\text { las campañas y la } \\
\text { gobernanza de los partidos } \\
\text { políticos. Antes de las } \\
\text { reformas, no había dinero } \\
\text { público para los partidos } \\
\text { políticos, lo que facilitó su } \\
\text { captura por intereses } \\
\text { privados, como lo confirman } \\
\text { los escándalos de } \\
\text { financiamiento político de } \\
2014-2015 \text { que precedieron } \\
\text { (y posibilitaron) las reformas. } \\
\text { A SERVEL, el regulador } \\
\text { electoral, se le otorgó más } \\
\text { poder y recursos, junto con } \\
\text { autonomía constitucional, } \\
\text { para hacer cumplir las } \\
\text { regulaciones de campaña } \\
\text { política y las nuevas } \\
\text { regulaciones para los partidos } \\
\text { políticos. Además, se } \\
\text { aumentaron las sanciones por } \\
\text { violaciones de la ley electoral }\end{array}$ \\
\hline
\end{tabular}

${ }^{19}$ https://www.elcomercio.com/actualidad/cne-ecuador-lgbti-voto-inclusivo.html

20 https://www.swissinfo.ch/spa/chile-Igbti--previsi\%C3\%B3n-_chile-registr\%C3\%B3-en-2020-un-aumentodel-14-7---en-casos-de-abusos-contra-Igbti/46456778 


\section{DERECHOELECTORAL}

\begin{tabular}{|c|c|c|c|}
\hline & $\begin{array}{l}\text { programáticas de todas las } \\
\text { candidaturas". Consagró, } \\
\text { además, una prohibición a } \\
\text { los sujetos políticos respecto } \\
\text { a "contratar publicidad en los } \\
\text { medios de comunicación y } \\
\text { vallas publicitarias". } \\
\text { De acuerdo al Código de la } \\
\text { Democracia, el } \\
\text { financiamiento "comprenderá } \\
\text { exclusivamente la campaña } \\
\text { propagandística en prensa } \\
\text { escrita, radio, televisión y } \\
\text { vallas publicitarias" y "el CNE } \\
\text { reglamentará en la } \\
\text { financiamiento según la } \\
\text { realidad de cada localidad". } \\
\text { Lo que dio pie a la creación } \\
\text { del Fondo de Promoción } \\
\text { Electoral con recursos que } \\
\text { provienen de los ciudadanos. } \\
\text { La reciente reforma electoral, } \\
\text { vigente desde febrero de } \\
2020, \text { triplica este fondo (se } \\
\text { incrementará en un } 230 \% \text { el } \\
\text { tope para la promoción } \\
\text { electoral de los postulantes a } \\
\text { la Presidencia de la } \\
\text { República21). } \\
\text { El monto aprobado para las } \\
\text { elecciones } 2021 \text { fue de } \\
\$ 91.000 .000 \text { (para } 13 \\
\text { millones de habitantes, } \\
\text { resulta un costo de } \$ 7 \text { por } \\
\text { votante, uno de los más } \\
\text { costosos de la región). }\end{array}$ & $\begin{array}{l}\text { Desde 1956, en Costa Rica } \\
\text { existe financiamiento } \\
\text { público de los partidos } \\
\text { políticos bajo la siguiente } \\
\text { modalidad: "los gastos en } \\
\text { que incurran los Partidos } \\
\text { Políticos para elegir los } \\
\text { miembros de los Poderes } \\
\text { Ejecutivo y Legislativo" } \\
\text { (Ley n. }{ }^{\circ} 2036 \text { ), } \\
\text { considerando la necesidad } \\
\text { de prevenir la influencia en } \\
\text { la política de los grupos de } \\
\text { poder económico y } \\
\text { garantizar la equidad en la } \\
\text { contienda y eliminando la } \\
\text { controversial práctica, } \\
\text { prohibida por el } \\
\text { Constituyente de } 1949, \text { de } \\
\text { cancelar las deudas del } \\
\text { partido triunfante mediante } \\
\text { deducciones salariales a los } \\
\text { funcionarios públicos } \\
\text { (Sobrado González, } 2011 \text { ). } \\
\text { El presupuesto para las } \\
\text { elecciones de Costa Rica en } \\
\text { el año } 2018 \text { fue de } \\
\$ 15.000 .000 \text { (para } 5 \\
\text { millones de habitantes, } \\
\text { resulta un costo de } \$ 3 \text { por } \\
\text { votante). En el caso } \\
\text { costarricense las } \\
\text { inversiones tecnológicas } \\
\text { significan una reducción en } \\
\text { el presupuesto siguiente, a } \\
\text { diferencia del caso } \\
\text { ecuatoriano en donde en } \\
\text { cada elección se invierte en } \\
\text { tecnología con incremento } \\
\text { gradual en cada jornada. }\end{array}$ & $\begin{array}{l}\text { y se ampliaron los plazos de } \\
\text { prescripción. } \\
\text { Estas reformas tuvieron } \\
\text { efectos positivos, ya que } \\
\text { involucraron a la sociedad } \\
\text { civil, en la Comisión } \\
\text { Presidencial Anticorrupción, } \\
\text { integrada por } 16 \text { expertos } \\
\text { diversos e independientes } \\
\text { que propusieron una } \\
\text { ambiciosa agenda durante el } \\
\text { período de la presidenta } \\
\text { Bachelet (Engel, 2019). }\end{array}$ \\
\hline
\end{tabular}

Nota: Elaborado con indicadores propuestos por la Comisión Global sobre Elecciones, Democracia y Seguridad (2012).

21 Este contenido ha sido publicado originalmente por Diario EL COMERCIO en la siguiente dirección: https://www.elcomercio.com/actualidad/asamblea-reformas-codigo-democracia-elecciones.html. 


\section{DERECHO ELECTORAL}

Manuel Alcántara Sáez y Ana Marcela Paredes Encalada

Anexo 2

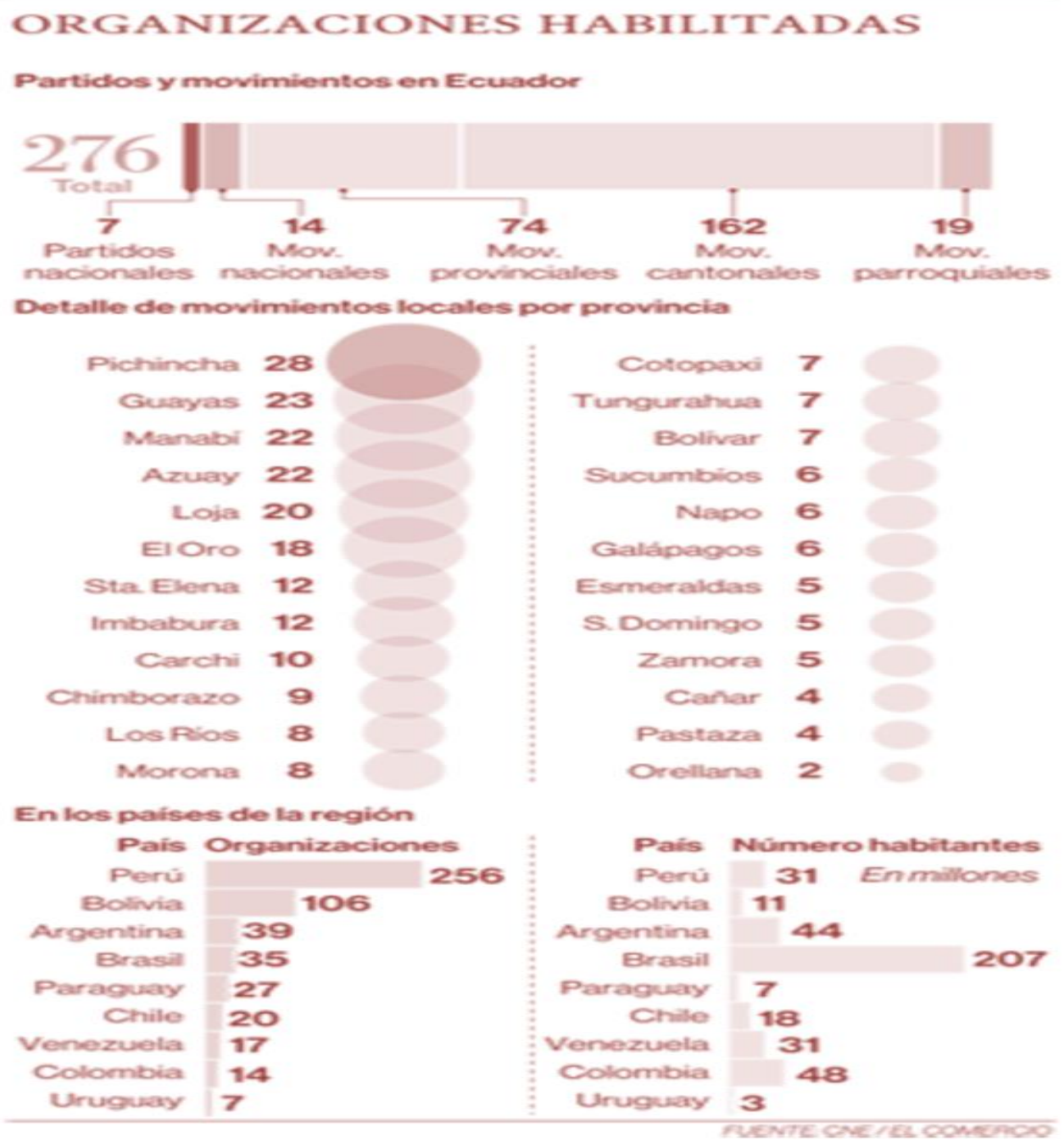

Figura 1. Organizaciones políticas Ecuador. Diario El Comercio. Agosto, 2018. 


\section{DERECHO ELECTORAL}

Anexo 3

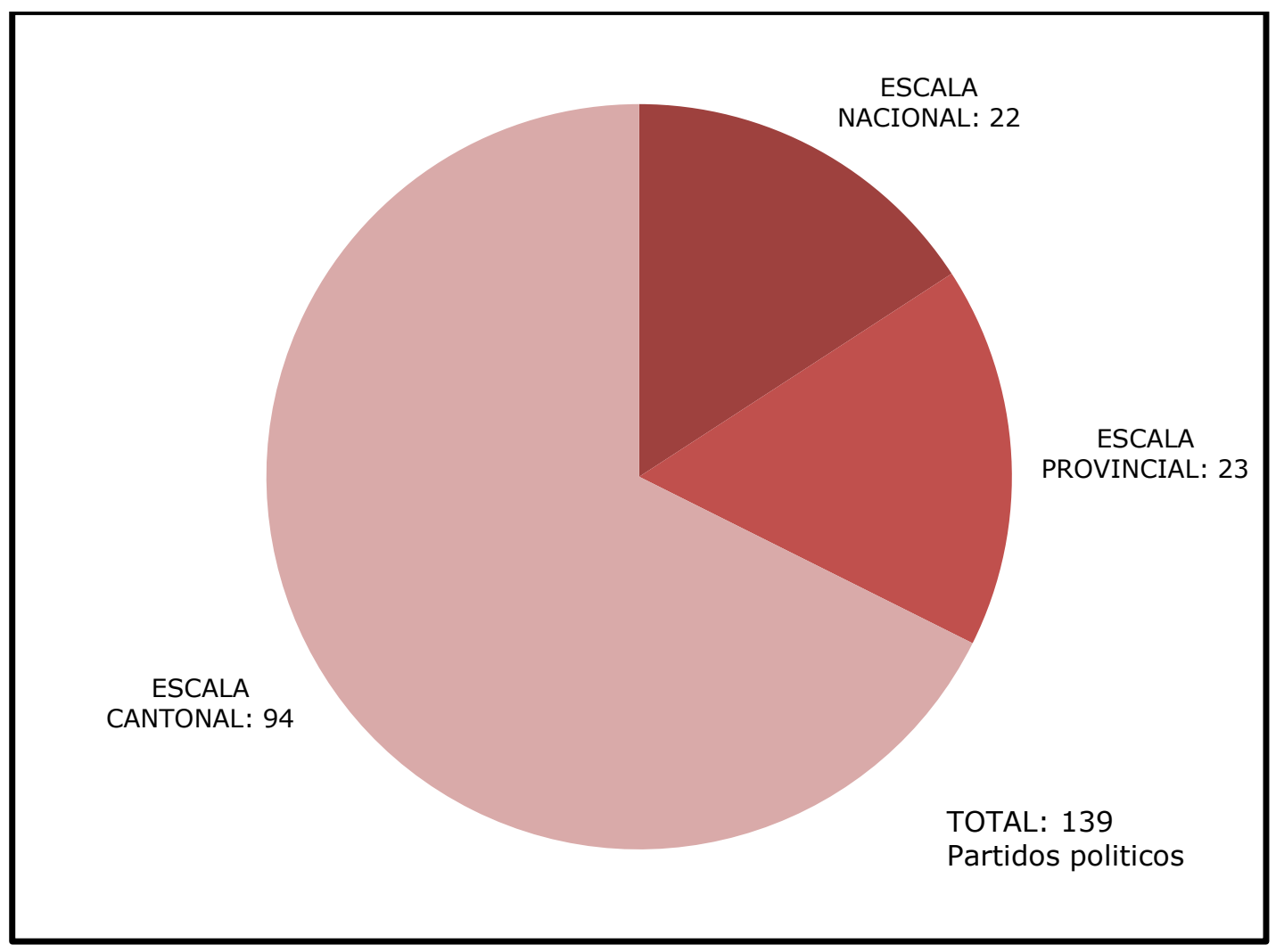

Figura 2. Organizaciones políticas Costa Rica. Elaborado con información del Tribunal Supremo de Elecciones Costa Rica. 


\section{DERECHO ELECTORAL}

Manuel Alcántara Sáez y Ana Marcela Paredes Encalada

\section{Anexo 4}

\begin{tabular}{|c|c|c|}
\hline & Partido & Año legal de fundación \\
\hline \& & Renovación Nacional & 1988 \\
\hline$\theta$ & Partido Demócrata Cristiano & 1988 \\
\hline PPD & Partido por la Democracia & 1988 \\
\hline $\boldsymbol{U} \boldsymbol{j}$ потия & Unión Demócrata Independiente & 1989 \\
\hline$(\mathrm{pls}$ & Partido Socialista de Chile & 1990 \\
\hline & Partido Radical de Chile & 1994 \\
\hline (2) & Partido Comunista de Chile & 2010 \\
\hline & Partido Humanista & 2014 \\
\hline$\Rightarrow$ & Evolución Política & 2016 \\
\hline 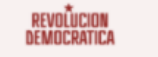 & Revolución Democrática & 2016 \\
\hline 3 & Federación Regionalista Verde Social & 2017 \\
\hline PTR & Partido de Trabajadores Revolucionarios & 2018 \\
\hline ॠ Procresistas & Partido Progresista de Chile & 2018 \\
\hline ciudadanos & Ciudadanos & 2018 \\
\hline Gpri & Partido Regionalista Independiente Demócrata & 2018 \\
\hline 앙 & Partido Ecologista Verde & 2018 \\
\hline & Comunes & 2018 \\
\hline (d) & Igualdad & 2018 \\
\hline $\begin{array}{l}\text { Partido } \\
\text { siberal }\end{array}$ & Partido Liberal de Chile & 2018 \\
\hline f & Nuevo Tiempo & 2019 \\
\hline ORepublicano & Partido Republicano de Chile & 2020 \\
\hline & Unión Patriótica & 2020 \\
\hline 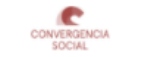 & Convergencia Social & 2020 \\
\hline 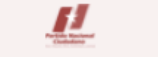 & Partido Nacional Ciudadano & 2020 \\
\hline & Partido Conservador Cristiano & 2020 \\
\hline 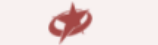 & Partido de la Gente & 2021 \\
\hline 8 & Centro Unido & 2021 \\
\hline
\end{tabular}

Figura 3. Partidos políticos en Chile. Elaborado con información de INFOGATE, octubre 2021. 